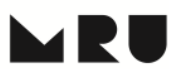

MYKOLO ROMERIO UNIVERSITETAS

\title{
DYNAMICS AND OPTIMAL CONTROL INVESTMENTS IN THE ECONOMIC GROWTH MODEL WITH CONDITION OF ECOLOGICAL BALANCE
}

\author{
Vasyl GRYGORKIV \\ Yurii Fedkovych Chernivtsi National University \\ E-mail: vasyl.hryhorkiv@gmail.com \\ Olena VINNYCHUK \\ Yurii Fedkovych Chernivtsi National University \\ E-mail: o.vinnychuk@chnu.edu.ua
}

doi:10.13165/IE-14-8-2-02

\begin{abstract}
Economic growth is seen as an integral part and one of the most important characteristics of economic development. The problems of considering the ecological balance in the economic growth model and allocating of the total investment in primary and secondary production are analyzed. On its basis, it is possible to analyze and forecast the optimal programs of economic development using policy instruments such as investment and consumption in the context of sustainable development in the eco-economic system.
\end{abstract}

Keywords: economic growth, economic growth model, sustainable development, ecological balance, optimal control

\section{JEL classification:}

O44 - Environment and Growth

E27 - Forecasting and Simulation: Models and Applications

\section{Introduction}

Economic growth is an old and a new field in economics, given the complexity of modern economic processes. Economic growth is seen as an integral part and one of the most important characteristics of economic development. Dealing with the economic growth 
Dynamics and Optimal Control Investments in the Economic Growth Model with Condition of Ecological Balance

problem implies the use of different models of economic growth. Models of economic growth can be used for analysis, planning and forecasting relationships between global economic indicators, which include national income, labor force, production facilities, etc. Economic growth is unlimited in terms of new researches, and every scientist can receive new results, changing entering estimates.

It should be noted that different aspects of economic growth modeling are described by Acemoglu, 2008; Charles, 1998; Novales \& Ruiz, 2014, Domar, 1957, Harrod, 2002, Samuelson, 1947, Solow, 1956, Ramsey, 1928 etc.

The main objectives of constructing economic growth models are: an explanation how the production factors influence the final result; to identify the contribution of each factor to ensuring the growth of the final result; optimal combination of instruments of growth patterns in the implementation of macroeconomic policies for economic growth of any country etc.

The results of correlation and regression analysis suggest that between GDP as the most common measures of economic growth and carbon dioxide emission is a direct relationship. Researches of the relationship between economic growth and harmful emissions are held by many scientists. In particular, David Cohen (Cohen, 2012) has argued the close relationship between economic growth and carbon emissions in his article. Karnjana Sanglimsuwan also has researched the relationship between $\mathrm{CO} 2$ emission and Gross domestic product based on econometric models (Sanglimsuwan, 2011). Ali Acaravci and Ilhan Ozturk in their paper "On the relationship between energy consumption, $\mathrm{CO}_{2}$ emissions and economic growth in Europe" (Acaravci et al, 2009) have examined the causal relationship between carbon dioxide emissions, energy consumption and economic growth by using autoregressive distributed lag bounds testing approach of cointegration for nineteen European countries.

This analysis of the relationship between economic growth and emissions suggests that it is necessary today to transition to environmentally sustainable patterns of production and consumption. The transition to environmentally sustainable patterns of production and consumption is to eliminate the correlation between economic growth and environmental degradation through improving the efficiency of natural resources use, improving the organizational and economic systems of production.

Considering the above said, we must modernize economic growth models taking into account the need for greening modern manufacturing in modern production conditions.

The problems of greening the economy are the most urgent problems today (Ryumina, 1980, Lyashenko, 1999, Grygorkiv, 2001, etc.). The strategy development of ecologically oriented management for the purpose of the transition to sustainable development is undoubtedly one of the priority tasks of the theory and practice of decision-making in economic growth models of any scale (regional or global). The successful resolution of these complex socio-eco-economic problems is impossible without scientific research aimed at the creation of appropriate methodological tools and methods for finding solutions and their implementing. 
In this article, the mathematical model of eco-economic growth of the ecologically balanced economy is proposed. This article extends the model that was proposed in the Grygorkiv \& Yakutova paper (Grygorkiv \& Yakutova, 2003).

In mathematical terms, this model belongs to a class of optimal control problems. Optimal control models have different views (Grygorkiv, 2011). However, they all include a criterion of optimality, dynamic equation of the phase variable and constraints on a variable that is a variable control. In this article the criterion of economic development in a fixed period of time is the maximization of the integrated non-productive consumption, i.e. dynamic equation of the phase variable is dynamic equation of productive capital, and the variable control is the investment ratio in the final product.

Similar models of optimal economic growth were built in articles of such scholars as S. Anit, V. Capasso, H. Kunze et al (Anit, 2014), Zuo, H. and Ai, D. (Zuo , 2011), Cherniwchan, J. (2012), Shieh, J-Y and Chen, J-H and Chang, S-H and Lai, C-C. (Shieh, 2014). All proposed models are models of optimal control problems, and they take into account the ecological components.

We offer to consider that the economy consists of basic (material) and secondary (auxiliary) productions. Auxiliary production destroys the pollutants that are formed during the functioning of primary production. Primary production associated with a production including pollution and auxiliary production (treatment plant) is concerned only with the destruction of pollutants. According to this statement, the total investments are allocated to primary and secondary production.

\section{The construction of economic growth model under conditions of ecological balance}

The dynamics of this ecologically balanced economy will be described by following variables: $t$ is the time variable, $X(t)$ is the gross product, $Y(t)$ is the final product, $I(t)$ are the total investments, $I_{b}(t)$ are the investments in basic (material) production, $I_{a}(t)$ are the investments in auxiliary production (treatment plants), $V(t)$ is the industrial consumption (the part of gross production that is recycled), $C(t)$ is the unproductive consumption, $K_{b}(t)$ is the capital of basic (material) production, $K_{a}(t)$ is the capital of auxiliary production, $L(t)$ is the manpower, $Z(t)$ is the pollution (e.g., the amount of pollutants in the environment at the moment $t), A_{b}(t)$ are the amortization charges to basic production assets, $A_{a}(t)$ are the amortization charges to auxiliary production assets.

Let us form the following basic assumptions:

1. The total investments at a time directly proportional to the final product: 
Dynamics and Optimal Control Investments in the Economic Growth Model with Condition of Ecological Balance

$$
I(t)=s(t) Y(t)
$$

where $s(t) \in[0,1]$ - the investment ratio in the final product.

2. Final product is determined using neoclassical production function (Grygorkiv, 2009):

$$
Y(t)=F\left(K_{b}(t), L(t)\right)
$$

3. The total investment are allocated to primary and secondary production:

$$
I(t)=I_{b}(t)+I_{a}(t) .
$$

It is the new assumption. It means that we need invest in auxiliary production to achieve the ecological balance.

4. The investments in basic and secondary (auxiliary) production are completely used for the capital depreciation and amortization:

$$
I_{b}(t)=\dot{K}_{b}(t)+A_{b}(t), I_{a}(t)=\dot{K}_{a}(t)+A_{a}(t) .
$$

5 . The amortization charges are directly proportional to the corresponding capital value at any time:

$$
A_{b}(t)=\mu_{b} K_{b}(t), \quad A_{a}(t)=\mu_{a} K_{a}(t)
$$

where:

$\mu_{b}, \mu_{a}$ are amortization coefficients $\left(\mu_{b}, \mu_{a} \in(0,1)\right)$.

6. The manpower is exogenous variable with sustainable growth rate $\eta=$ const :

$$
L(t)=L_{0} e^{\eta t}
$$

7. The industrial consumption expenditures are directly proportional to the value of gross production by a factor $a(0<a<1)$ :

$$
V(t)=a X(t)
$$

8. The criterion of economic development in a fixed period of time $[0, T]$ is the maximization of the integrated non-productive consumption

$$
\int_{0}^{T} e^{-\delta t} C(t) d t \mapsto \max ,
$$


where $\delta=$ const $>0$.

8. The economy being considered is developed under stable ecological balance conditions (Crelle, 1988). That is the state when the volume of contamination is independent of the time:

$$
P(t)=P_{\min }=\text { const }
$$

Ecological balance (9) is formalized as follows:

$$
\alpha(X(t))-\beta\left(K_{a}(t)\right)=\gamma(P(t)) \equiv \gamma_{0} \equiv \text { const }
$$

where $\alpha(X(t))$ is the function of produced pollution, $\beta\left(K_{a}(t)\right)$ is the function of eliminated pollution, $\gamma(P(t))$ is the function of the self-purifying pollution.

Before formalizing this variant of the economic dynamics model in terms of sustainable ecological balance let us extend equation (10). Pollution is the result of economic activity because it increases simultaneously with final product $Y(t)$. Pollution reduction is possible only through the capital use $K_{a}(t)$ (for example, building systems for wastewater treatment or emissions).

It is logical to assume that the amount of disposed pollution also increases with increasing capital $K_{a}(t)$. In addition, there is a nature self-purification, which is monotonically increasing function of pollution $P(t)$. Assuming that produced pollution, reduced pollution and contamination, which nature self-purify, described by the appropriate functions $\alpha(Y(t)), \beta\left(K_{a}(t)\right)$ and $\gamma(P(t))$, we obtain a general expression for pollution (Crelle, 1988).

Therefore,

$$
P(t)=\int_{0}^{t}\left[\alpha(Y(\tau))-\beta\left(K_{a}(\tau)\right)-\gamma(P(\tau))\right] d \tau
$$

Ecologic balance (9) means that $\dot{P}(t) \equiv 0$, that is

$$
\alpha(Y(t))-\beta\left(K_{a}(t)\right)=\gamma(P(t))
$$

From (9) and (12) that in the state of ecological balance:

$$
\gamma(P(t))=\gamma\left(P_{\min }\right)=\gamma_{0}
$$


i.e. the same amount of purified contamination is also a constant. Of course, one can also select nonlinear versions of this function, for example $P(t)=\gamma_{0} \mathrm{e}^{-r t}$ (level of pollution decreases exponentially with time).

Moreover, let us assume that the functions $\alpha(X(t))$ and $\beta\left(K_{z}(t)\right)$ are linear:

$$
\begin{aligned}
& \alpha(X(t))=\alpha_{0}+\alpha_{1} X(t), \\
& \beta\left(K_{z}(t)\right)=\beta_{0}+\beta_{1} K_{z}(t),
\end{aligned}
$$

where the constants $\alpha_{0}, \beta_{0}, \alpha_{1}, \beta_{1}$ and $\gamma_{0}$ play an important role in the actual estimation of the influence of the ecological factor on economic development.

Substituting (13) and (14) in (12), we obtain:

$$
\alpha_{1} Y(t)-\beta_{1} K_{a}(t)=\varepsilon_{0},
$$

where $\varepsilon_{0}=\gamma_{0}-\alpha_{0}+\beta_{0}$. Formula (15) reflects the balance of pollution flow and purifying in the absence of economic activity. A priori, we note that all the above constants play an important role because the acceptable level of the pollution is a policy issue.

Let us introduce the specific indices: $k=K_{b} / L, y=Y / L, c=C / L$. Using the fact that the production function is neoclassical, we obtain the equation:

$$
\dot{k}=\rho(t, k),
$$

where

$$
\rho(t, k)=\left\{\left[s-\frac{\alpha_{1}}{\beta_{1}}\left(\mu_{a}+\eta\right)\right] f(k)-\left(\mu_{b}+\eta\right) k+\frac{\mu_{a} \varepsilon_{0} e^{-\eta t}}{\beta_{1} L_{0}}\right\} \cdot\left(1+\frac{\alpha_{1}}{\beta_{1}} f^{\prime}(k)\right)^{-1} .
$$

Equation (16) is the equation of the capital primary production dynamics (capital-labor ratio - the value of capital per unit of labor). Since $Y(t)=C(t)+I(t)$ and taking into account (1), (8), (16) and the boundary conditions, which the trajectory of economic dynamics must satisfy, we propose the following model of optimal economic dynamics in conditions of economic balance: 


$$
\left\{\begin{array}{l}
\int_{0}^{T} e^{-\delta t}(1-s(t)) f(k) d t \mapsto \max , \\
\dot{k}=\rho(t, k), \\
k(0)=k^{(0)}, k(T) \geq k^{(T)}, \\
0 \leq s(t) \leq 1,
\end{array}\right.
$$

where $k^{(0)}$ and $k^{(T)}$ are specified and positive constants. In mathematical terms, the model (17) belongs to a class of optimal control models ( $k$ - phase variable, $S$ - control variable). To investigate this model we have used the sufficient conditions for optimality by Krotov (Krotov, 1990).

Thus, economic growth is determined by the set of various factors, including increasing the number of productive resources (dynamics of capital primary production), increasing their quality and improving methods of their use. It usually requires investment. Therefore, investments act as the main regulator of economic growth.

\section{Empirical Analysis}

The aim of the empirical analysis is to find a solution on the base of the model (17). For this reason, we have built the algorithm of the optimal control problems solution and have designed the application using Matlab software. This algorithm allows to write all components of the optimal process $\left(s^{*}(t), k^{*}(t)\right), t \in[0, T]$ in explicit analytic form, of course, under certain constraints on the model parameters.

The algorithm above specifies the procedure for computing moments in time $\tau^{*}, \tau^{* *}$ , changes in the value of investments and bound intervals of time $\left[t_{0}, \tau^{*}\right],\left[\tau^{*}, \tau^{* *}\right]$, $\left[\tau^{* *}, T\right]$, during on which it is necessary to choose different size of control value (the investment ratio in the final product) to achieve optimal switching of the control system from the initial state to the final. In economic terms, the essence of the optimal control is planning investments in production, which is simultaneously accumulated waste disposal.

For the simulation, we used a specific example in which production function was based on the real statistics on Ukraine $f(k)=0,1924 k^{0,8616}$ (State Statistics Service of Ukraine, 2014).

The optimal trajectory of the model (17) is based on the algorithm and illustrated in Fig. 1.

Figure 1: Illustration of the optimal trajectory for eco-economic growth model (17) 
Dynamics and Optimal Control Investments in the Economic Growth Model with Condition of Ecological Balance

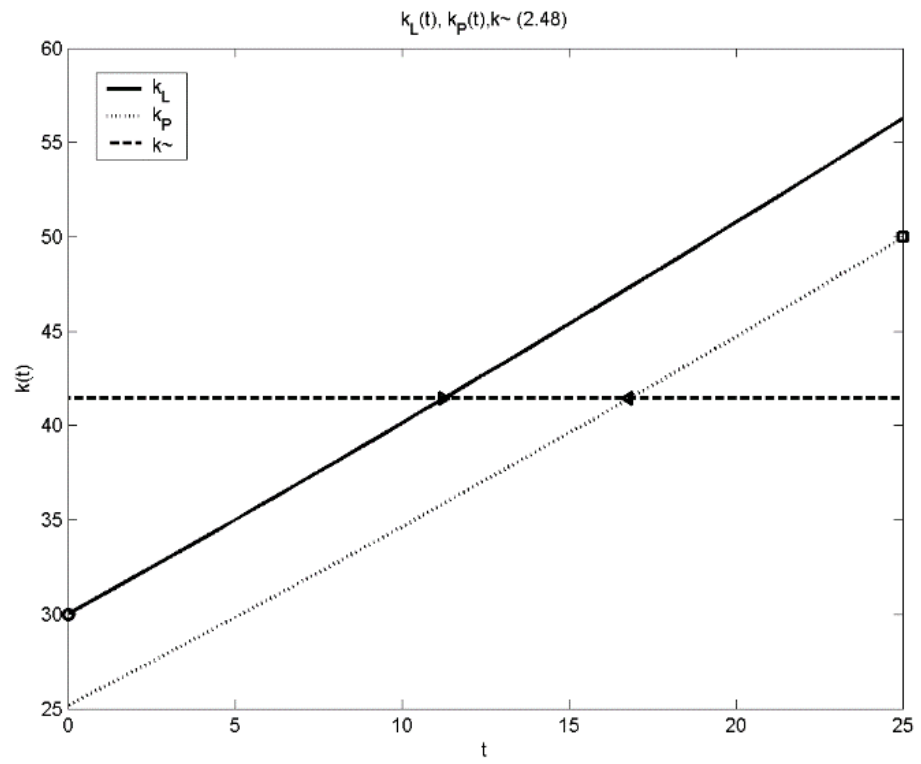

The series of numerical experiments were held, and the economic growth under the conditions of the model (17) was modeled. Optimal control combines movement trajectory $k_{\Lambda}(t)$, moving at a constant level of the capital-labor ratio $\tilde{k}$, and the movement trajectory $k_{\Pi}(t)$ (Fig. 1), which fully corresponds to the task. At the same time, moments of changes in the investment management are defined according to the algorithm. In other words, during the time interval $[0,25]$ from the initial state $k^{(0)}=30$ we can get on turnpike at time $\tau^{*}$ $=11,25$, and in order to achieve the desired end state $k^{(T)}=50$, it gets off the turnpike at time $\tau^{* *}=16.77$. Thus, during the periods of time $[0 ; 11,25]$ and $[16,77 ; 25]$ all investments are allocated only to the economic development and support of ecological balance. 


\section{Conclusions}

The constructed model can be used for the detection of management patterns of ecoeconomic systems and analysing the final state of economic dynamics trajectory. It can also be used for the content of relevant economic decisions affecting the dynamics of capital and its distribution at a given level taking into account the ecological balance.

From the point of view of the decision-making person, this model allows to optimize the process of planning, implementation and optimal control of changes in the investment in production systems. Conclusions, derived from computational experiments, not only illustrate the effectiveness of the chosen method of optimal control, but also reveal patterns of change of economic phenomena associated with investing in the production and processing in terms of increase or decrease production and increase or reduction of pollution.

Also, experimental research of the model shows that the admissible control points and the desired change of control are strongly dependent on the model parameters and the selected production function.

It is be noted that latest studies are about sustainable development that is means we must consider and research economy in the context of ecological balance. Therefore, modern approaches to economic growth should receive involving ecological component.

\section{Acknowledgment}

This project has been funded with support from the European Commission (No. 204521-1-2011-1-LT-ERA MUNDUS-EMA21). This publication reflects the views only of the authors, and Commission cannot be held responsible for any use which may be made of the information contained therein.

\section{References}

1. Acaravci, A., Ozturk I. (2009). On the relationship between energy consumption, $\mathrm{CO}_{2}$ emissions and economic growth in Europe. The 3rd International Conference on Sustainable Energy and Environmental Protection, SEEP 2009, from http://www.sciencedirect.com/ science/article/pii/S0360544210003737

2. Acemoglu, D. (2008). Introduction to Modern Economic Growth. Department of Economics, Massachusetts Institute of Technology : 1008 p.

3. Anit, S., Capasso, V., Kunze, H., D. La Torre (2014). Dynamics and optimal control in a spatially structured economic growth model with pollution diffusion and environmental taxation. Appl. Math. Lett., from http://dx.doi.org/10.1016/j.aml.2014.11.001.

4. Charles, I. Jones (1997). Introduction to Economic Growth. W.W. Norton \& Company : $202 \mathrm{p}$.

5. Cherniwchan, J. (2012). Economic growth, industrialization, and the environment. Resource and Energy Economics, 34 : 442-467. 
Dynamics and Optimal Control Investments in the Economic Growth Model with Condition of Ecological Balance

6. Cohen D. (2012). The Close Relationship between Economic Growth and Carbon Emissions, from http://oilprice.com/Finance/the-Economy/The-Close-Relationship-betweenEconomic-Growth-and-Carbon-Emissions.html.

7. Crelle, V. (1988). Economic growth in the depletion of natural resources and environmental protection, Moscow : 198-228. (in Russian).

8. Domar, E. D. (1957). Esays in the Theory of Economic Growth. Oxford University Press, Oxford : $272 \mathrm{p}$.

9. Grygorkiv, V. and Yakutova O. and Tymku S. (2003) Model of optimal ecoeconomic dynamics. Reports of NAS of Ukraine, 9 : 59-64. (in Ukrainian).

10. Grygorkiv, V. Economic modeling. Chernivtsi, 2009, pp. 195-199. (in Ukrainian). Ukrainian).

11. Grygorkiv, V. Optimal control of the economy. Chernivtsi, 2011, pp. 65-75. (in

12. Grygorkiv, V.S. (2001). On the problem of economic-mathematical modeling of eco-economic interaction and sustainable development. Scientific Bulletin Of Chernivtsi University: Series "Economics", 113: 106 - 110. (in Ukrainian).

13. Harrod, R. (2000). On the theory of economic dynamics. Radio and Communications, Moscow : $160 \mathrm{p}$.

14. Krotov, V. F, Lagosha, B. A, Lobanov, S. M. (1990). Foundations of Optimal Control Theory, Moscow : 430 p. (in Russian).

15. Lyashenko, I.M. (2006). Fundamentals of mathematical modeling of economic, ecological and social processes: teach. guidances. / I.M., Lyashenko, M.V., Korobov, A. Carpenter. - Stockholm: Training book. Bogdan : 304 p. (in Ukrainian).

16. Novales, A., Fernandez, E., Ruiz, J. (2014). Economic Growth : Theory and Numerical Solution Methods. Springer-Verlag Berlin Heidelberg: 558 p.

17. Ramsey, F. A. (1928). Mathematical Theory of Saving. Economic Journal, 38 (152): 543-559.

18. Rumina, E.V. (2006) Analysis of ecological and economic interactions. - Moscow: Nauka: 159 p. (in Russian).

19. Samuelson, P. A. (1947). Foundations of Economic Analysis. Cambridge, Harvard University Press : $460 \mathrm{p}$.

20. Sanglimsuwan K. (2011). Carbon Dioxide Emissions and Economic Growth: An Econometric Analysis. International Research Journal of Finance and Economics, from http:// www.eurojournals.com /IRJFE_67_09.pdf.

21. Shieh, J-Y and Chen, J-H and Chang, S-H and Lai, C-C. (2014). Environmental consciousness, economic growth, and macroeconomic instability. International Review of Economics and Finance, $34: 151-160$.

22. Solow, R. M. (1956). A Contribution to the Theory of Economic Growth. Quarterly Journal of Economics, 70 (1): 65-94.

23. State Statistics Service of Ukraine (2014). National Accounts. Retrieved November 1, 2014 from: http://www.ukrstat.gov.ua. 
24. Zuo, H. and Ai, D. (2011). Environment, energy and sustainable economic growth. Procedia Engineering, $21: 513$ - 519.

\section{About the Authors:}

Vasyl Grygorkiv - Prof. Dr., Yurii Fedkovych Chernivtsi National University, Ukraine, Department of Economics.

Research interests: mathematical modeling of environmental economics, social processes and systems.

Olena Vinnychuk - Ph.D., Associate Professor, Yurii Fedkovych Chernivtsi National University, Ukraine, Department of Economics.

Research interests: mathematical and quantitative methods in environmental economics, social processes, and systems. 